Article

\title{
A Facile Method to Prepare a Superhydrophobic Magnesium Alloy Surface
}

\author{
Jiyuan Zhu * and Haojie Jia \\ College of Mechanical and Control Engineering, Guilin University of Technology, Guilin 541004, China; \\ 18656959510@163.com \\ * Correspondence: zhujy@glut.edu.cn
}

Received: 21 July 2020; Accepted: 9 September 2020; Published: 10 September 2020

\begin{abstract}
The application of superhydrophobic materials has been handicapped by complex processes and poor environmental friendliness. Magnesium alloys are widely used in daily production due to their low density and good casting properties. A facile and environmentally friendly method was proposed to prepare a superhydrophobic layer with coral-like microstructure on the surface of AZ91D magnesium alloy by high temperature heating. The prepared superhydrophobic surface has a contact angle of $159.1^{\circ}$ and a rolling angle of $4.8^{\circ}$. The corrosion current of superhydrophobic surface has been reduced by about two orders of magnitude relative to the magnesium alloy substrate and its inhibition efficiency is $96.94 \%$, which demonstrates its great corrosion resistance. In addition, the superhydrophobic surface has great thermal stability. When the temperature rises to $190{ }^{\circ} \mathrm{C}$, the contact is still above $150^{\circ}$. Excellent self-cleaning and advantages in preparation efficiency, environmental protection and cost-effectiveness will boost its good application prospects.
\end{abstract}

Keywords: superhydrophobic; wettability; thermal stability; corrosion resistance

\section{Introduction}

Found on many animals and plants, such as lotus leaf surface, mosquito's eyes, and water strider's legs [1-3], superhydrophobicity is a common phenomenon in nature. Material surfaces, with a water contact angle greater than $150^{\circ}$ and a rolling angle less than $10^{\circ}$, are usually called superhydrophobic surfaces [4]. Superhydrophobic surfaces are gaining more and more research attention due to their great properties of anticorrosion [5-7], drag reduction [8-10], self-cleaning [11,12] and anti-icing [13]. Many methods to prepare superhydrophobic surfaces have been investigated, which mainly include chemical etching [14], electrodeposition [15], laser engraving [16], anodizing [17,18] etc. The excellent performance of superhydrophobic surfaces offer potential applications in many fields, such as microfluidic control [19], corrosion inhibition [20], nondestructive transportation [21], drag reduction [22], and so on. Superhydrophobic technology can be applied on the metal surface to slow down the corrosion rate of the metal surface to a certain extent [23].

Magnesium, and its alloys, are widely used in automobiles, aerospace parts, medical treatment and electronic communication due to its good ductility and conductivity, excellent specific stiffness and strength, and other advantages [24-27]. However, the low standard potential, poor corrosion resistance and high chemical activity have limited its application to a certain extent [28,29]. Surface treatment [30] has been an important attempt to improve the properties of magnesium alloy. The inherent water-repellent properties of superhydrophobic surfaces can reduce the exchange rate of metal ions and the electrochemical oxidation rate, thus greatly improving the corrosion resistance of metals and alloys [31]. Therefore, superhydrophobic preparation on the surface of magnesium alloy can effectively protect its surface against corrosion and broaden the use of magnesium alloy. Bao Yin et al. [32] etched magnesium alloy with nitric acid and a cupric nitrate mixed solution, and then modified 
it with a low surface energy solution and prepared the superhydrophobic surface with a contact angle of $162.1^{\circ}$. Liu et al. [33] prepared the superhydrophobic surface of magnesium alloy with excellent durability. Liu et al. [34] prepared the superhydrophobic surface of magnesium alloy with excellent corrosion resistance on AZ31 magnesium alloy by micro arc oxidation and immersion in stearic acid ethanol solution. Kang et al. [35] electrodeposited AZ31 superhydrophobic magnesium alloy with good self-cleaning properties in the mixed solution of ceric nitrate and stearic acid ethanol. $\mathrm{Wu}$ [36] et al. prepared superhydrophobic films with regular hexagon microstructure and excellent friction resistance on the surface of magnesium alloy. Liu et al. [37] prepared inorganic organic hybrid superhydrophobic films with $\mathrm{pH}$-sensitive "core-shell" nanostructure inhibitors on AZ61 magnesium alloy by dip-coating method. However, these preparation methods are complex in technology [33,36], poor in environmental friendliness [32] and high in research cost [34], which are not conducive to the practical application of magnesium alloy. Therefore, it is of great value to study the preparation of superhydrophobic and anticorrosive surfaces of magnesium alloy with low cost and risk.

In this study, the surface of superhydrophobic magnesium alloy (SMA) was prepared by stearic acid treatment after stable heating of magnesium alloy sheet in a muffle furnace. The prepared super-hydrophobic layer has good corrosion protection performance to the magnesium alloy substrate. The samples show excellent self-cleaning and high temperature resistance. After high temperature heating, it can still maintain good superhydrophobic properties, which greatly broadens the application scope and service life of magnesium alloy. This preparation method does not need expensive equipment, complicated preparation processes, and substances such as fluoride and strong acid and alkali that cause hazards to the environment. It has excellent environmental performance, economy and high efficiency. At present, there are few articles about the preparation of superhydrophobic surfaces by directly heating the substrate to form a microstructure. This method is a new attempt to prepare a superhydrophobic surface of magnesium alloy. All these advantages will boost its good application prospects.

\section{Materials and Methods}

\subsection{Materials}

The $15 \mathrm{~mm} \times 15 \mathrm{~mm} \times 3 \mathrm{~mm}$ AZ91D magnesium alloys (8.5-9.5\% Al, 0.45-0.9\% Zn, 0.17-0.4\% Mn) were used as material and purchased via the Hebei Tengshi metal materials Co., Ltd. (Xingtai, China). Stearic acid (SA) and sodium chloride $(\mathrm{NaCl})$ were supplied by Xilong Scientific Co., Ltd. (AR, Shantou, China). Anhydrous ethanol was supplied by Fuyu Fine Chemical Co., Ltd. (Tianjin, China).

\subsection{Methods}

The AZ91D magnesium alloy was successively grounded with SiC papers from 600 to 1200 grit until it shone. After this, it was put into anhydrous ethanol and deionized water for ultrasonic cleaning for $10 \mathrm{~min}$ to remove the oil and impurities. Then, $0.3 \mathrm{~g}$ of stearic acid solid particles and $29.7 \mathrm{~g}$ of anhydrous ethanol were added into a $50 \mathrm{~mL}$ beaker to prepare $30 \mathrm{~g}$ of $1 \mathrm{wt}$. $\%$ ethanol stearic acid solution.

The pre-treated magnesium alloy (MA) substrates were put into a muffle furnace (KSL-1700X, Hefei kejing Material Technology Co., Ltd, Hefei, China) with the heat holding temperatures of $365^{\circ} \mathrm{C}$, $375^{\circ} \mathrm{C}, 385^{\circ} \mathrm{C}$ and $395^{\circ} \mathrm{C}$, and the magnesium alloy was covered with a crucible to prevent irreversible effects on the surface structure caused by the fast temperature rise. The heating time was set as $100 \mathrm{~min}$, and the heat holding time was set as $30 \mathrm{~min}, 60 \mathrm{~min}, 90 \mathrm{~min}$ and 120min, respectively. After heating, the MA were removed and cooled to room temperature. Subsequently, the MA was soaked in a pre-prepared solution of ethanol and stearic acid for $10 \mathrm{~min}$. Finally, the MA was removed and dried in the air. 


\subsection{Sample Characterization}

The morphologies and chemical composition of the samples were characterized by field emission scanning electronic microscopy (SEM, SU5000, HITACHI, 5.0 KV, Tokyo, Japan) quipped with an energy dispersive X-ray spectrometer (EDS, $15 \mathrm{KV}$, xflash6110, Bruker, Leipzig, Germany). The phase structure of the samples was studied with an X-ray diffractometry (XRD, smartlab9, Rigaku Corporation; Target: CuKa; 40 KV, 150 mA; Wavelength: 1.54056, Tokyo, Japan). The chemical compositions and valence states of the samples were measured using X-ray photoelectronspectroscopy (XPS, 250Xi, Thermo scientific, Waltham, Massachusetts, America) with the Al K $\alpha$ X-raysource ( $\mathrm{h} v=1486.6 \mathrm{eV}$ ). The chemical compositions were also determined by Fourier transform infrared spectroscopy (FTIR, IRAffinity-1S, Shimadzu Corporation, $4000-450 \mathrm{~cm}^{-1}$, Tokyo, Japan). The static contact angle (CA) and sliding angle (SA) were measured by a contact angle measuring instrument (SDC-200, Sindin Precision Instrument Co., Ltd., Dongguan, China). Average contact angle measurements were obtained at 4 different locations using $8 \mu \mathrm{L}$ droplets (deionized water). All electrochemical measurements were performed using a CS2350H electrochemical workstation (Wuhan Corrtest Instruments Corp., Ltd, Wuhan, China) using a conventional three electrode set-up with a platinum plate as the auxiliary electrode, a $\mathrm{Ag} / \mathrm{AgCl}$ (Saturated $\mathrm{KCl}$ ) electrode as the reference electrode, and the sample to be tested as the test electrode. The exposure area of the tested sample was $1 \mathrm{~cm}^{2}$ and the tests were done at room temperature. Polarization curves were obtained in $3.5 \mathrm{wt} \% \mathrm{NaCl}$ solution. The measured potential was from $-0.5 \mathrm{~V}$ to $1.5 \mathrm{v}$ vs. open circuit potential at a scan rate of $1 \mathrm{mVs}^{-1}$. Before the test, the sample was in contact with the solution for $30 \mathrm{~min}$ to ensure the stability of the sample surface.

\section{Results and Discussion}

\subsection{Wettability}

Temperature is a critical factor affecting the growth of coral-like microstructures on the surface of magnesium alloy in this experiment. In order to prepare a SMA surface with excellent properties, the effect of heating temperature on surface wettability of MA is studied. The influences of different heating temperatures, $355{ }^{\circ} \mathrm{C}, 365{ }^{\circ} \mathrm{C}, 375{ }^{\circ} \mathrm{C}, 385^{\circ} \mathrm{C}$ and $395{ }^{\circ} \mathrm{C}$, on the contact angle of the superhydrophobic surface are shown in the Figure 1. after $60 \mathrm{~min}$ in heat preservation.
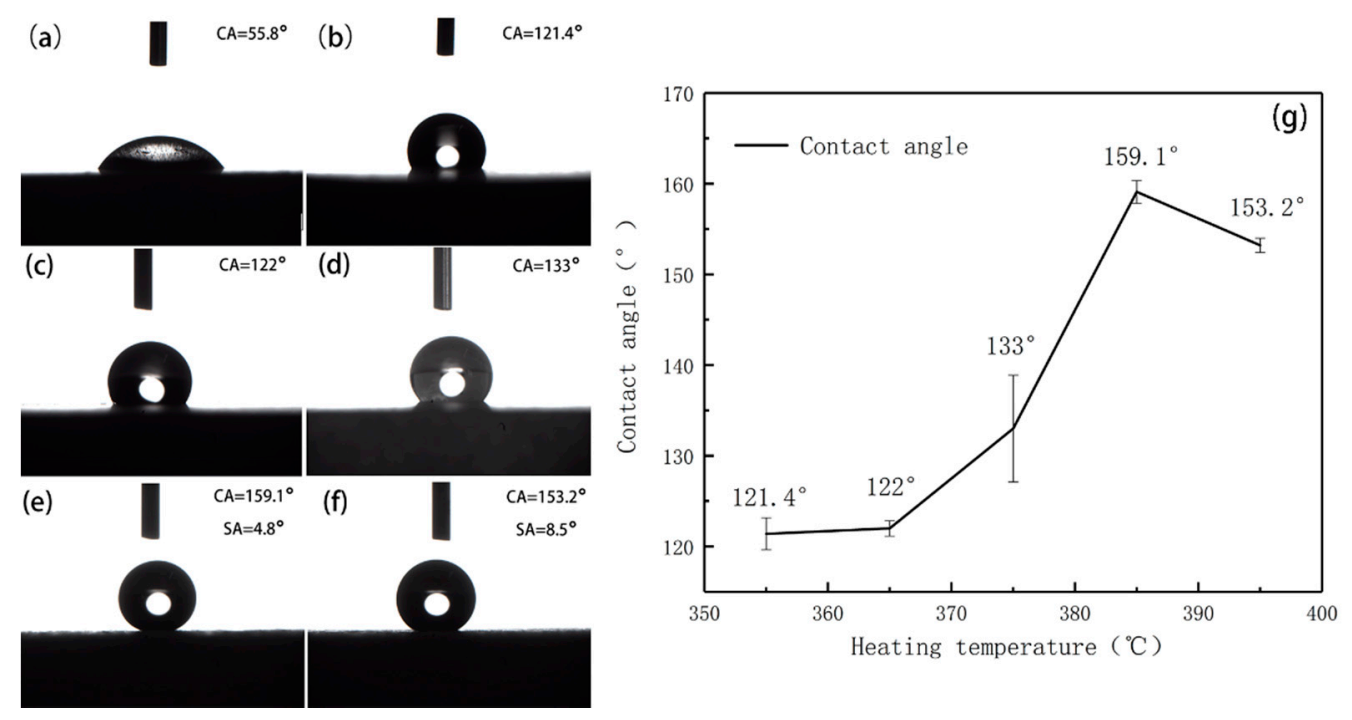

Figure 1. Contact angle images of the magnesium substrate (a) and samples with different heating temperatures: (b) $355^{\circ} \mathrm{C}$, (c) $365^{\circ} \mathrm{C}$, (d) $375^{\circ} \mathrm{C}$, (e) $385^{\circ} \mathrm{C},\left(\right.$ f) $395^{\circ} \mathrm{C}$; Contact angle change trend (g). 
It can be seen from Figure 1a that the surface of the magnesium alloy gains the hydrophobic property when the heating temperature is $365^{\circ} \mathrm{C}$. As it increases to $375^{\circ} \mathrm{C}$, the contact angle gradually increases to $133^{\circ}$, as shown in Figure $1 \mathrm{~b}$. In Figure 1c, when the heating temperature increases to $385^{\circ} \mathrm{C}$, the static water contact angle of the droplets on the magnesium alloy surface reaches $159.1^{\circ}$. As the temperature continues to increase to $395^{\circ} \mathrm{C}$, the contact angle decreases to $153.2^{\circ}$ in Figure $1 \mathrm{~d}$. When the heating temperature is $405^{\circ} \mathrm{C}$, the MA melts into powder. Therefore, the optimal heating temperature is $385^{\circ} \mathrm{C}$ when the holding time is $60 \mathrm{~min}$.

The effect of heat treatment holding time on the surface wettability of MA is studied. Under the same heating temperature of $385^{\circ} \mathrm{C}$, the influences of the heat holding time on the contact angle of the MA surface are shown in the Figure 2.

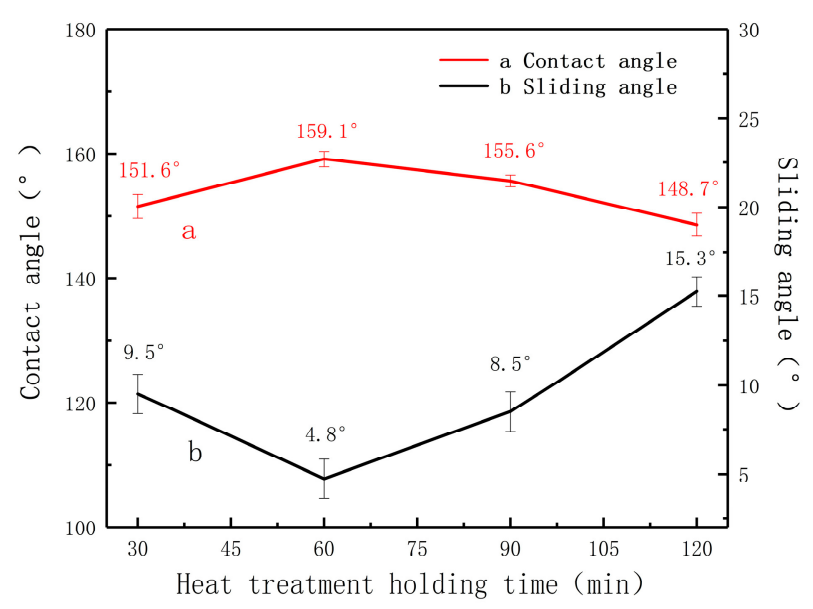

Figure 2. Contact angle of the samples with different heat holding time $\left(385^{\circ} \mathrm{C}\right): 30 \mathrm{~min}, 60 \mathrm{~min}, 90 \mathrm{~min}$ and $120 \mathrm{~min}$.

It can be seen from Figure 2 that the static contact angle of water droplets on the magnesium alloy surface increases with the increase in heat holding time, and it reaches $159.1^{\circ}$ when the heat treatment time is $60 \mathrm{~min}$. As the heat holding time continues to grow, the contact angle gradually decreases.

The investigation shows that the water contact angle of magnesium alloy changes relatively little under the same heating temperature and different heat holding times; however, the contact angle of magnesium alloy varies greatly with the constant heat holding time and different heating times. Therefore, the heating time is one of the important factors affecting the wettability of the magnesium alloy surface. At the same time, a heating temperature of $385{ }^{\circ} \mathrm{C}$ and a heat holding time of $60 \mathrm{~min}$ are the best conditions for this experiment.

\subsection{Surface Morphology}

To investigate the significant difference in wettability between the SMA surface and the untreated magnesium alloy, we compare the scanning electron microscope (SEM) images of samples processed in different conditions. As can be seen in Figure $3 a, b$, the surface is relatively flat and a sparse small microstructure begins to grow under $365^{\circ} \mathrm{C}$. At $375^{\circ} \mathrm{C}$, it can be observed in Figure $3 \mathrm{c}$, d that more microstructures begin to grow on the surface of the magnesium alloy and the wettability gradually improves. As the temperature rises to $385^{\circ} \mathrm{C}$, it can be observed in Figure $3 \mathrm{e}, \mathrm{f}$ that a layer of dense coral-like microstructure is formed on the magnesium alloy surface. The existence of pores in this structure, like the Cassie model, makes the air become trapped between grains when droplets contact the surface, which enhances the hydrophobicity of the material surface [2,38]. At $395^{\circ} \mathrm{C}$, it can be seen from Figure $3 \mathrm{~g}$, h that a considerable part of the original structure similar to the Cassie model is broken, leaving fewer microstructures to trap the air and prevent the wetting of the droplets, which is one of the causes of the decline of its wettability [39]. 

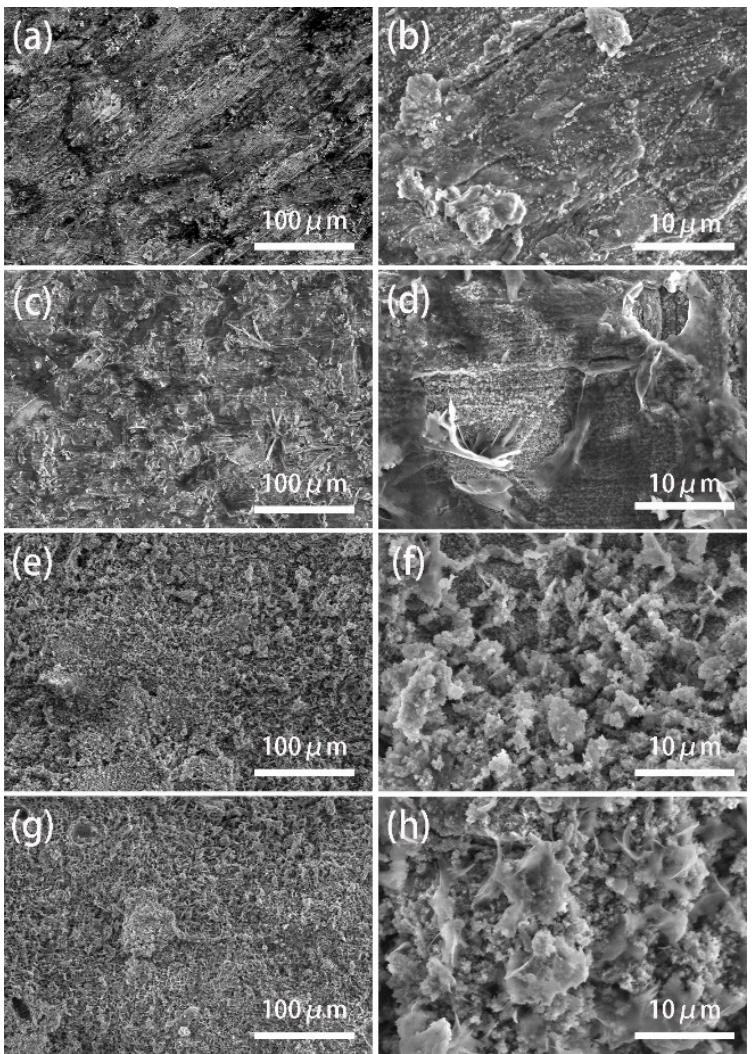

Figure 3. SEM images of the sample surfaces with different heating temperature: $(\mathbf{a}, \mathbf{b}) 365{ }^{\circ} \mathrm{C}$; (c,d) $375^{\circ} \mathrm{C} ;(\mathbf{e}, \mathbf{f}) 385^{\circ} \mathrm{C} ;(\mathbf{g}, \mathbf{h}) 395^{\circ} \mathrm{C}$.

\subsection{Surface Composition Analysis}

In this section, the superhydrophobic surface is all prepared at a heating temperature of $385^{\circ} \mathrm{C}$ and a holding time of $60 \mathrm{~min}$.

Figure 4a shows the FT-IR spectra of the superhydrophobic surface and stearic acid. It can be seen from the figure that, after the modification of stearic acid, absorption peaks exist at the wavelengths of $2850 \mathrm{~cm}^{-1}$ and $2915 \mathrm{~cm}^{-1}$ corresponding to the symmetric and antisymmetric methylene stretching vibrations, respectively, and this indicates the presence of hydrophobic long-chain alkyl on the sample surface [40-42]. Results demonstrate that stearic acid has been successfully bonded to the surface of the magnesium alloy substrate.
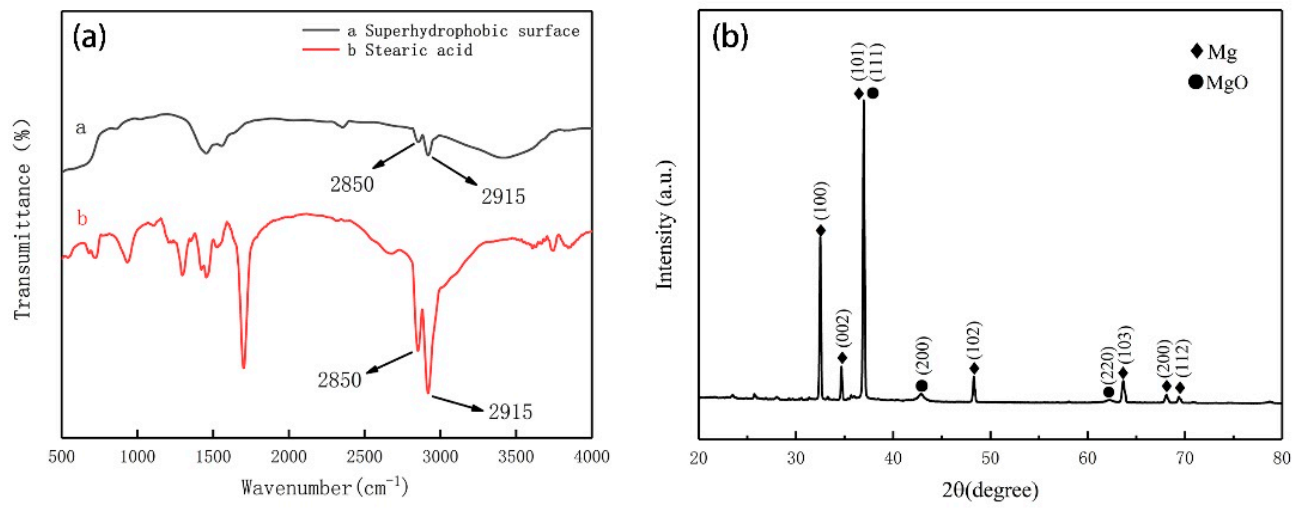

Figure 4. (a) FT-IR infrared spectra of the superhydrophobic magnesium alloy (SMA) surface and stearic acid, and (b) XRD diffraction patterns. 
The XRD patterns of samples are illustrated in Figure 4b. According to the JADE (software, JADE6, Jade company, New Zealand) peaks, the XRD results show that the SMA displays characteristic peaks at $2 \theta$ of $32.5^{\circ}, 34.7^{\circ}, 36.9^{\circ}, 48.3^{\circ}, 63.7^{\circ}, 68.1^{\circ}$ and $69.4^{\circ}$, which are attributed to the (100), (002), (101), (102), (103), (200) and (112) crystalline planes of Mg [43]. In addition, the SMA displays characteristic peaks at $2 \theta 36.9^{\circ}, 42.9^{\circ}$ and $62.3^{\circ}$, which are attributed to the (111), (200) and (220) crystalline planes of $\mathrm{MgO}[44]$.

We use EDS to help analyze the elemental composition of the SMA surface. Figure 5a shows the results of the superhydrophobic magnesium alloy (SMA) that was heated at $385^{\circ} \mathrm{C}$ and kept warm for $60 \mathrm{~min}$. The SEM surface morphology is shown in Figure 5b. As shown in Figure 5c-e, the $\mathrm{Mg}, \mathrm{O}$ and $\mathrm{C}$ elements uniformly distribute on the surface of the SMA.
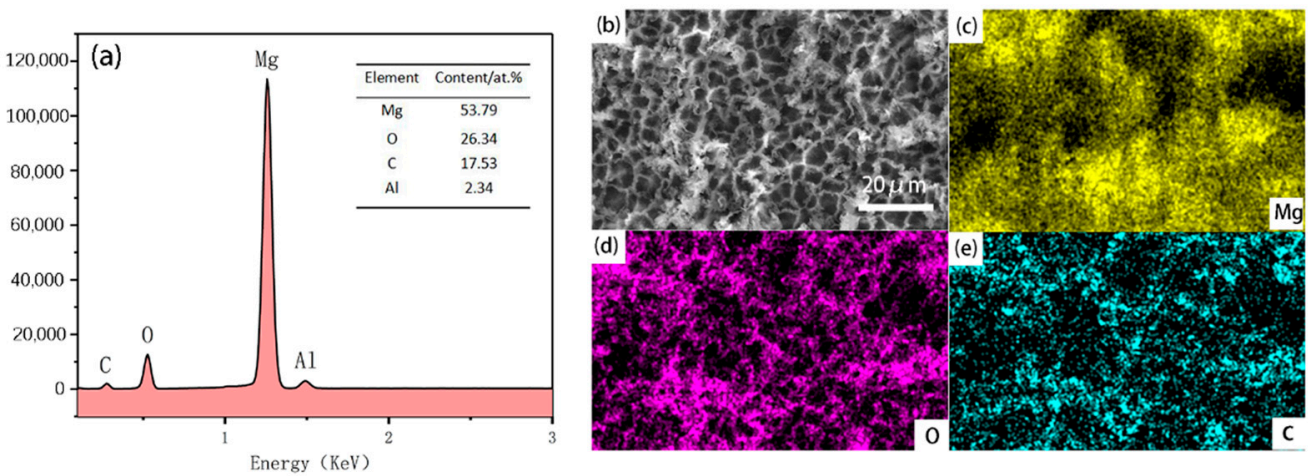

Figure 5. (a) Results of EDS on the SMA surface; (b) SEM morphology; (c-e) EDS elemental mapping images of the SMA surface.

To further determine the chemical compositions of the surface, an XPS test is conducted. Figure 6 shows the XPS survey spectrum of MA and SMA. It can be seen from the Figure $6 \mathrm{a}, \mathrm{b}$ that the $\mathrm{Mg}, \mathrm{Al}$, $\mathrm{O}, \mathrm{C}$ elements exist on the surface of MA and SMA. The possible reasons for the disappearance of the $\mathrm{N}$ element are as follows. First, the very small amount of $\mathrm{N}$ element on the superhydrophobic surface is blocked by the precipitation of $\mathrm{Mg}$ and the formation of $\mathrm{MgO}$. Second, the AlN originally present on the surface of the magnesium alloy may react to form $\mathrm{Al}_{2} \mathrm{O}_{3}$ and $\mathrm{N}_{2}$ after high-temperature heating treatment.
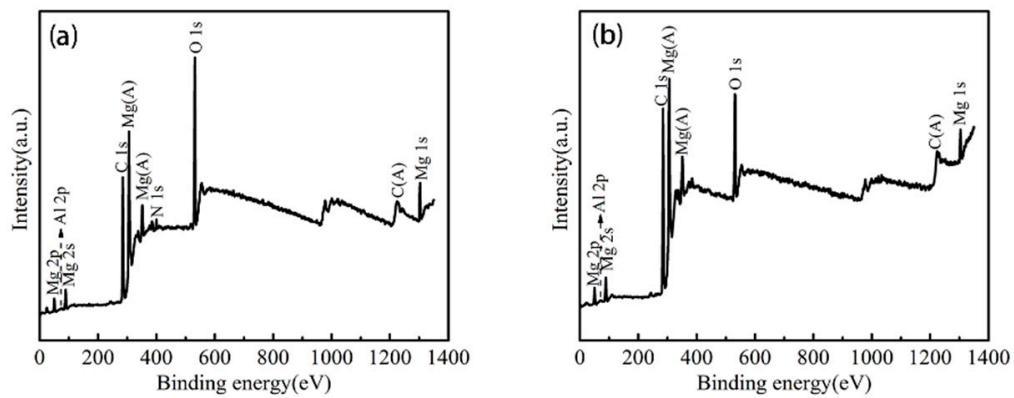

Figure 6. XPS survey spectrum of (a) magnesium alloy (MA), (b) superhydrophobic magnesium alloy (SMA).

The detailed surface composition and chemical state, evaluated using high resolution spectra, were acquired for individual elemental peaks and deconvoluted using XPS peak software. As shown in Figure $7 \mathrm{a}$, the deconvoluted $\mathrm{Mg}$ 1s core level peak consists of the magnesium $(1303.3 \mathrm{eV})$. The deconvoluted $\mathrm{Mg}$ 1s core level peak (Figure $\mathrm{7b}$ ), consists of the $\mathrm{Mg}$ and $\mathrm{MgO}$ corresponding to $1303.3,1304.2 \mathrm{eV}$, respectively. The deconvoluted $\mathrm{Al} 2 \mathrm{p}$ peak indicates the presence of $\mathrm{Al}_{2} \mathrm{O}_{3}(74.7 \mathrm{eV})$, AlN $(70.3 \mathrm{eV})$ bonds in Figure $7 \mathrm{c}$ and $\mathrm{Al}_{2} \mathrm{O}_{3}(74.4 \mathrm{eV})$, $\mathrm{AlN}(70.6 \mathrm{eV})$ in Figure $7 \mathrm{~d}$. AlN may be an 
impurity. In sure 7e, the peaks at 531.4 and $532.3 \mathrm{eV}$ can be assigned to $\mathrm{Al}-\mathrm{O}$ and $\mathrm{C}-\mathrm{O}$. In Figure $7 \mathrm{f}$, the peaks at 529.9, 531.2, 532.1 eV can be assigned to $\mathrm{Mg}-\mathrm{O}, \mathrm{Al}-\mathrm{O}$ and $\mathrm{C}-\mathrm{O}$, respectively. These indicate that $\mathrm{MgO}$ is mainly formed during the reaction.
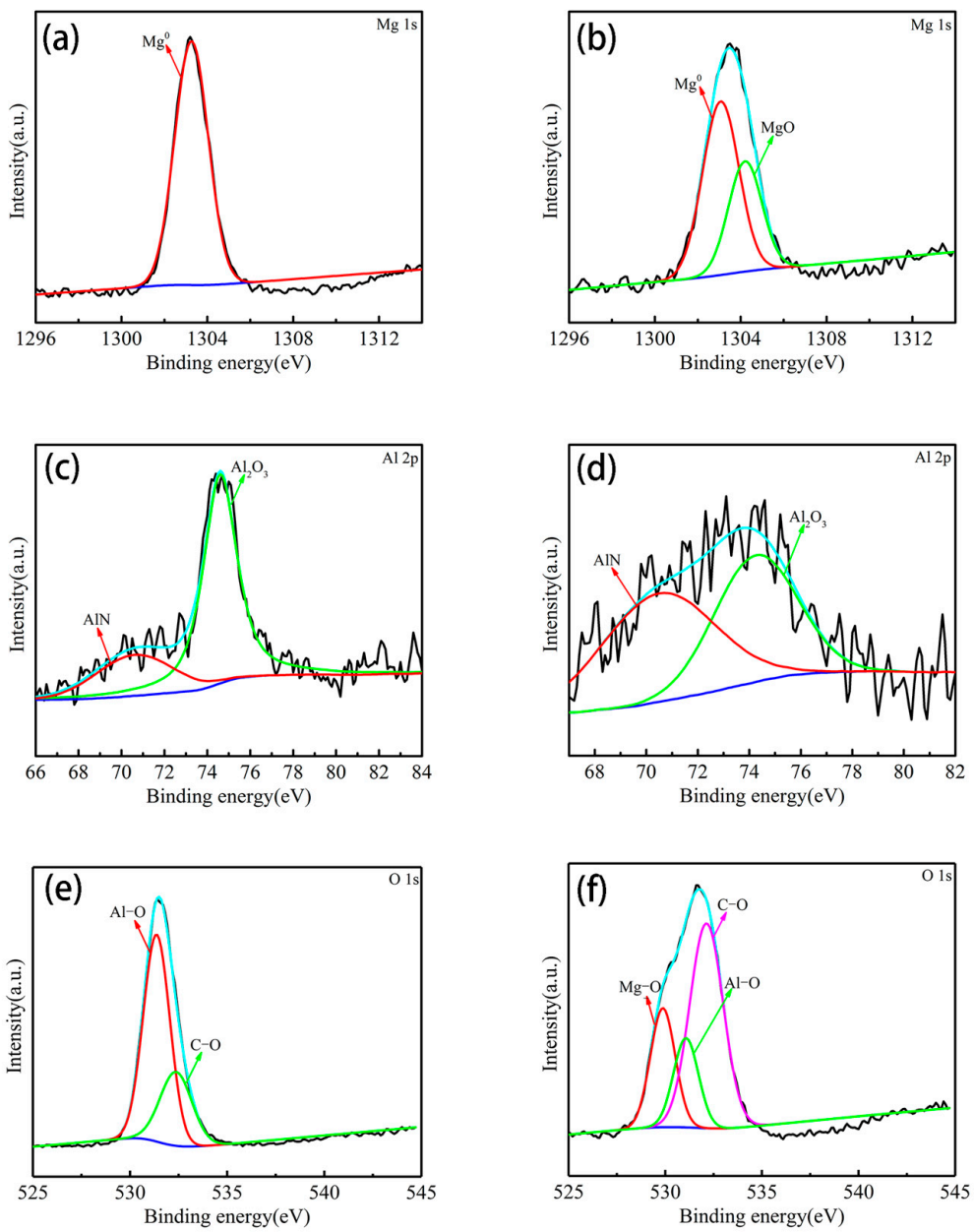

Figure 7. XPS high resolution spectrum of (a) Mg 1s, (c) Al 2p; (e) O 1s core level spectrum of MA, (b) $\mathrm{Mg} 1 \mathrm{~s}$ and (d) $\mathrm{Al} 2 \mathrm{p}$; (f) $\mathrm{O}$ 1s core level spectrum of SMA.

\subsection{Corrosion Behavior}

The potentiodynamic polarization curves of both bare and superhydrophobic magnesium alloys are presented in Figure 8.

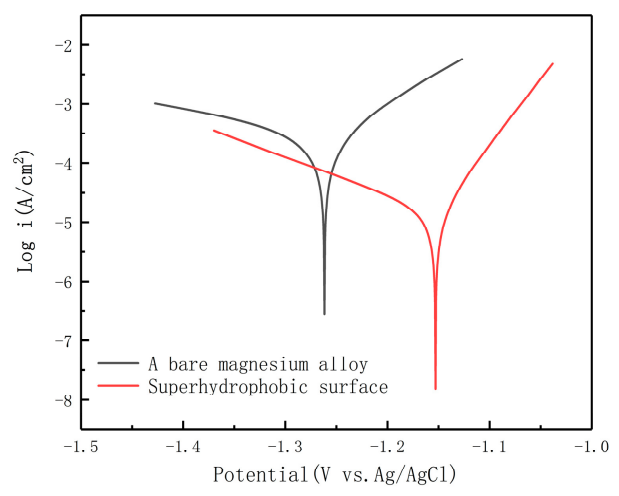

Figure 8. Potentiodynamic polarization curves of the AZ91D Mg substrate and the superhydrophobic surface in the $3.5 \mathrm{wt}$. \% NaCl solution. 
In order to confirm the reliability of the electrochemical parameters, the polarization tests were performed in three times and the average values were obtained. Table 1 shows the corrosion current density ( $\left.\mathrm{I}_{\text {corr }}\right)$ and corrosion potential $\left(\mathrm{E}_{\mathrm{corr}}\right)$, which were determined using the extrapolation method. Compared with the untreated AZ91D magnesium alloy surface, the corrosion potential of the SMA surface changes to a positive direction (from $-1.2525 \mathrm{~V}$ vs. $\mathrm{Ag} / \mathrm{AgCl}$ to $-1.1495 \mathrm{~V} \mathrm{vs}$. $\mathrm{Ag} / \mathrm{AgCl}$ ), and the corrosion current density decreases by almost two orders of magnitude (from $3.1713 \times 10^{-4} \mathrm{~A} \cdot \mathrm{cm}^{-2}$ to $9.7053 \times 10^{-6} \mathrm{~A} \cdot \mathrm{cm}^{-2}$ ). The presence of the superhydrophobic coating further blocks the contact between the sodium chloride solution and the magnesium alloy substrate. This makes the superhydrophobic surface relatively difficult to be corroded, which may be one of the reasons for the positive shift of corrosion potential. In this table, the corrosion efficiency of the inhibitor $(\eta)$ [45], which is calculated via the following Equation (1), is also provided.

$$
\eta=\frac{i_{\text {corr }}^{0}-i_{\text {corr }}}{i^{0}{ }_{\text {corr }}} \times 100 \%
$$

where $i_{\text {corr }}^{0}$ and $i_{\text {corr }}$ are corrosion current densities of MA and SMA, respectively. According to the calculation, the inhibition efficiency of the SMA is $96.94 \%$. The results show that the superhydrophobic layer can effectively enhance the corrosion resistance of the substrate.

Table 1. Electrochemical dates of the polarization curves obtained from the samples.

\begin{tabular}{cccc}
\hline Sample & $\mathrm{E}_{\text {corr }}$ (V vs. Ag/AgCl) & $\mathbf{I}_{\text {corr }} \mathbf{( A / \mathbf { c m } ^ { 2 } )}$ & $\eta \mathbf{~ ( \% )}$ \\
\hline AZ91D & -1.2525 & $3.1713 \times 10^{-4}$ & - \\
SMA & -1.1495 & $9.7053 \times 10^{-6}$ & 96.94 \\
\hline
\end{tabular}

\subsection{Self-Cleaning Effect}

To test the self-cleaning properties of a sample, water was dropped on the surface covered with fine sand as shown in Figure 9a. As a water droplet dripped onto the surface of the sample, under the action of surface tension, the water droplet and fine sand mixed and formed a cloudy droplet, which continued to roll until it fell off the surface as depicted in Figure 9b-d. The angle between the sample and the plane was about 12 degrees during testing. This angle was greater than the rolling angle on the surface of the SMA, so the droplet rolled down smoothly. The result indicates that the surface of the film modified by stearic acid has low adhesion and good self-cleaning performance.
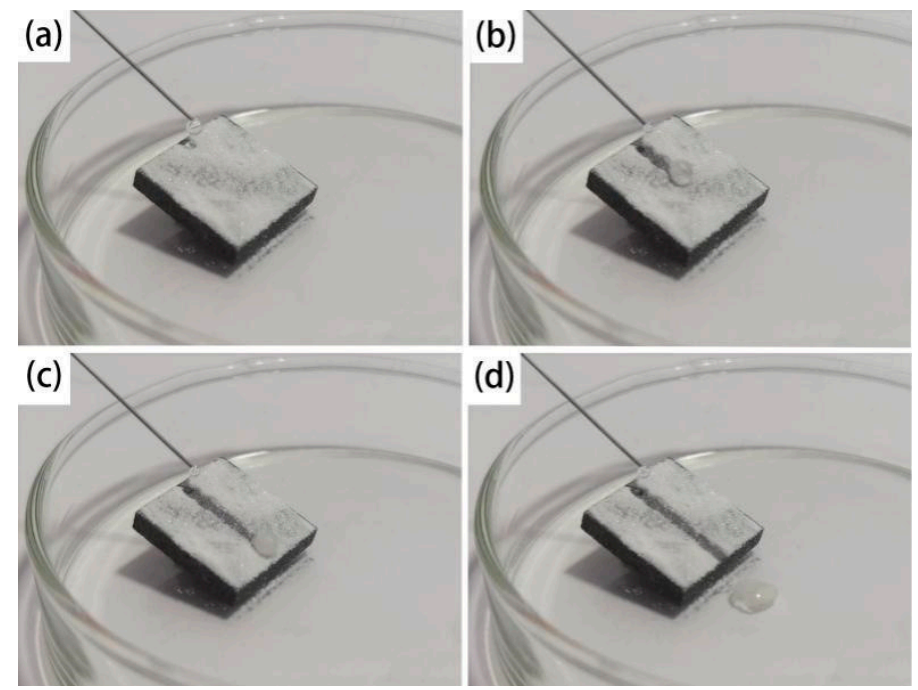

Figure 9. Self-cleaning performance of the SMA surface. (a) Dripping; (b) Water drop contact; (c) Water drop rolling; (d) Water droplets roll out. 


\subsection{Bouncing Performance Test}

The red ink flow from the syringe was utilized to test the bouncing performance of the SMA surface. The water flowed out of the syringe and fell on the surface of the sample. The water rebounded on the surface of the sample and popped out to the other side. Figure 10a,b show the whole process. After the test, there was no liquid residue on the surface, which shows the excellent water repellency of the SMA surface.
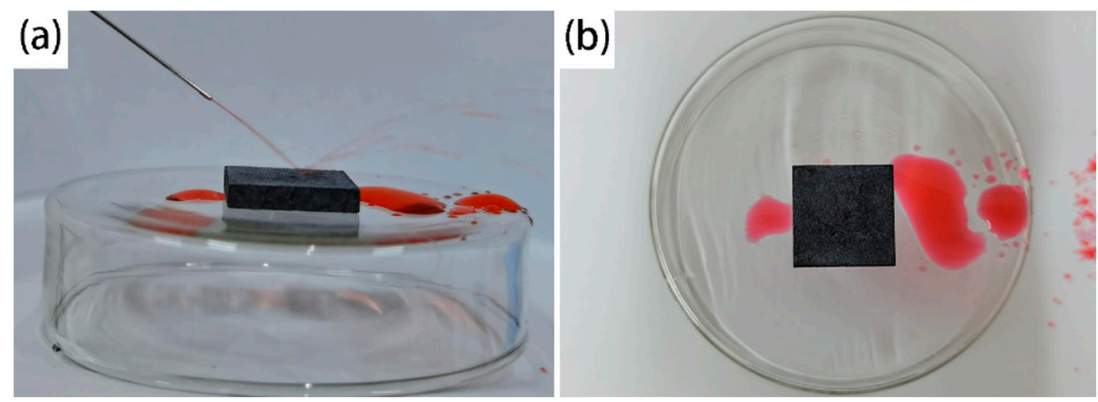

Figure 10. Bouncing performance of the SMA surface. (a) Red ink bouncing; (b) No residual liquid on the surface.

\subsection{Thermal Stability}

The thermal stability experiment of the superhydrophobic surface is of great significance in practical application, especially when magnesium alloy parts are used at an elevated temperature. Figure 11 shows the change trend of contact angle of the SMA surface heated continuously for one hour at different temperatures.

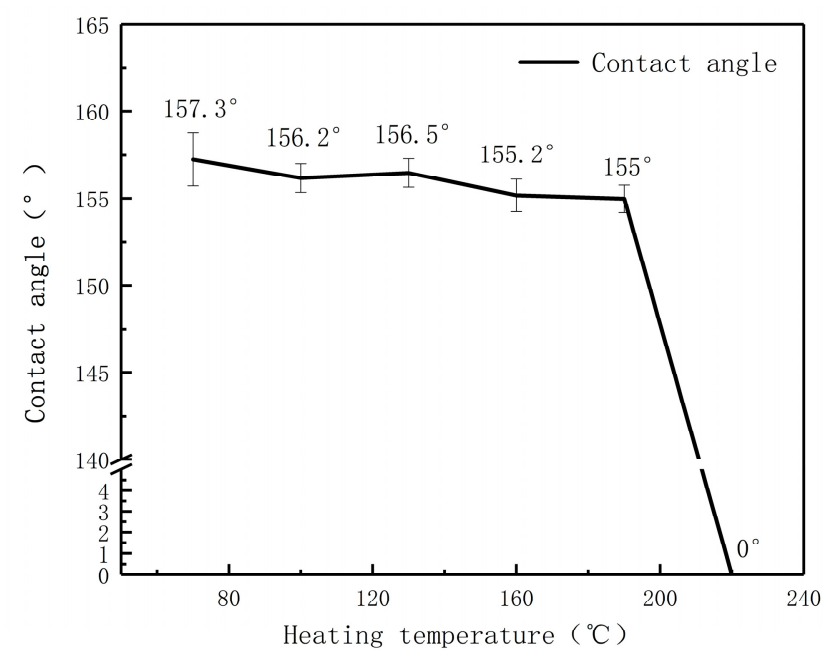

Figure 11. Thermal stability test of the SMA.

The figure shows that the contact angle of the SMA surface decreases with the increase in temperature, and the contact angle remains above $150^{\circ}$ when the continuous heating temperature is $190^{\circ} \mathrm{C}$. When the temperature rises to $220^{\circ} \mathrm{C}$, the surface of the sample changes into the superhydrophilic state. According to the research, the stearic acid molecular chains gradually break down, carbonize and decompose at $160{ }^{\circ} \mathrm{C}$ [46]. However, due to the fine microstructure on the surface of the SMA, its decomposition rate is slowed down. When the temperature rises to $220^{\circ} \mathrm{C}$, the molecular chains completely break, carbonize and decompose, which is the main reason for its transformation from superhydrophobic to superhydrophobic. Soaked in stearic acid ethanol solution for $10 \mathrm{~min}$, the surface contact angle reaches $152.9^{\circ}$ again and it changes to the superhydrophobic state. 


\section{Conclusions}

In this experiment, AZ91D is heated at high temperature and modified with stearic acid to prepare SMA. The contact angle and rolling angle are $159.1^{\circ}$ and $4.8^{\circ}$, respectively. The SMA surface has excellent superhydrophobicity and self-cleaning properties, due to its coral-like microstructure and low surface energy. The thermal stability experiment of SMA shows that the contact angle is still above $150^{\circ}$ when the temperature rises to $190{ }^{\circ} \mathrm{C}$. When the heating temperature is $220^{\circ} \mathrm{C}$, the surface of magnesium alloy changes to the superhydrophobic state. After being soaked in ethanol stearic acid mixed solution, the sample surface is reverted to the superhydrophobic state. These results indicate the SMA has thermal stability and reusability. The SMA sample exhibits a lower corrosion rate compared with the MA sample, revealing that it possessed excellent corrosion resistance. To sum up, this experiment is simple and environment-friendly. It does not require highly polluting reagent, expensive equipment and materials. With the excellent self-cleaning, anti-corrosion, thermal stability and durability, the obtained SMA will have more extensive application and development prospects.

Author Contributions: Conceptualization, J.Z.; Methodology, J.Z.; Writing-Review and editing, J.Z. WritingOriginal draft, H.J.; Software, H.J.; Investigation, H.J. All authors have read and agreed to the published version of the manuscript.

Funding: This work was funded by the Natural Science Foundation of Guangxi (Grant 2019GXNSFBA245069), Middleaged and Young Teachers \& apos; Basic Ability Promotion Project of Guangxi (Grant 2019KY0290), Guilin University of Technology (Grant GUTQDJJ20176612037).

Conflicts of Interest: The authors declare that they have no known competing financial interest or personal relationships that could have appeared to influence the work reported in this paper.

\section{References}

1. Xu, L.; Yao, X.; Zheng, Y. Direction-dependent adhesion of water strider's legs for water-walking. Solid State Sci. 2012, 14, 1146-1151. [CrossRef]

2. Feng, L.; Li, S.; Li, Y.; Li, H.; Zhang, L.; Zhai, J.; Song, Y.; Liu, B.; Jiang, L.; Zhu, D. Super-Hydrophobic Surfaces: From Natural to Artificial. Adv. Mater. 2002, 14, 1857-1860. [CrossRef]

3. Gao, X.; Yan, X.; Yao, X.; Xu, L.; Zhang, K.; Zhang, J.; Yang, B.; Jiang, L. The Dry-Style Antifogging Properties of Mosquito Compound Eyes and Artificial Analogues Prepared by Soft Lithography. Adv. Mater. 2007, 19, 2213-2217. [CrossRef]

4. Hooda, A.; Goyat, M.; Pandey, J.K.; Kumar, A.; Gupta, R. A review on fundamentals, constraints and fabrication techniques of superhydrophobic coatings. Prog. Org. Coat. 2020, 142, 105557. [CrossRef]

5. Zheng, Z.; Liu, Y.; Bai, Y.; Zhang, J.; Han, Z.; Ren, L. Fabrication of biomimetic hydrophobic patterned graphene surface with ecofriendly anti-corrosion properties for $\mathrm{Al}$ alloy. Colloids Surf. A Physicochem. Eng. Asp. 2016, 500, 64-71. [CrossRef]

6. Li, H.; Yu, S.; Han, X.; Zhao, Y. A stable hierarchical superhydrophobic coating on pipeline steel surface with self-cleaning, anticorrosion, and anti-scaling properties. Colloids Surf. A: Physicochem. Eng. Asp. 2016, 503, 43-52. [CrossRef]

7. Ye, Y.; Zhang, D.; Li, J.; Liu, T.; Pu, J.; Zhao, H.; Wang, L. One-step synthesis of superhydrophobic polyhedral oligomericsilsesquioxane-graphene oxide and its application in anti-corrosion and anti-wear fields. Corros. Sci. 2019, 147, 9-21. [CrossRef]

8. Pakzad, H.; Liravi, M.; Moosavi, A.; Nouri-Borujerdi, A.; Najafkhani, H. Fabrication of durable superhydrophobic surfaces using PDMS and beeswax for drag reduction of internal turbulent flow. Appl. Surf. Sci. 2020, 513, 145754. [CrossRef]

9. Alinovi, E.; Bottaro, A. Apparent slip and drag reduction for the flow over superhydrophobic and lubricant-impregnated surfaces. Phys. Rev. Fluids 2018, 3, 124002. [CrossRef]

10. Rastegari, A.; Akhavan, R. The common mechanism of turbulent skin-friction drag reduction with superhydrophobic longitudinal microgrooves and riblets. J. Fluid Mech. 2018, 838, 68-104. [CrossRef]

11. Qu, M.; Liu, S.; He, J.; Feng, J.; Yao, Y.; Hou, L.; Ma, X.; Liu, X. Fabrication of recyclable superhydrophobic materials with self-cleaning and mechanically durable properties on various substrates by quartz sand and polyvinylchloride. RSC Adv. 2016, 6, 79238-79244. [CrossRef] 
12. Jia, Y.; Chen, B.; Zhang, M.; Li, X.; Yang, J. A novel colorful sepiolite-based superhydrophobic coating with excellent mechanical and chemical stability and self-cleaning property. Mater. Lett. 2019, 254, 340-343. [CrossRef]

13. Ruan, M.; Li, W.; Wang, B.; Deng, B.; Ma, F.; Yu, Z. Preparation and Anti-icing Behavior of Superhydrophobic Surfaces on Aluminum Alloy Substrates. Langmuir 2013, 29, 8482-8491. [CrossRef] [PubMed]

14. Ganne, A.; Lebed, V.O.; Gavrilov, A.I. Combined wet chemical etching and anodic oxidation for obtaining the superhydrophobic meshes with anti-icing performance. Colloids Surf. A Physicochem. Eng. Asp. 2016, 499, 150-155. [CrossRef]

15. Shen, L.; Xu, M.; Jiang, W.; Qiu, M.; Fan, M.; Ji, G.; Tian, Z.-J. A novel superhydrophobic Ni/Nip coating fabricated by magnetic field induced selective scanning electrodeposition. Appl. Surf. Sci. 2019, 489, 25-33. [CrossRef]

16. Li, J.; Zhou, Y.; Wang, W.; Xu, C.; Ren, L. Superhydrophobic Copper Surface Textured by Laser for Delayed Icing Phenomenon. Langmuir 2020, 36, 1075-1082. [CrossRef] [PubMed]

17. Zang, J.; Yu, S.; Zhu, G.; Zhou, X. Fabrication of superhydrophobic surface on aluminum alloy 6061 by a facile and effective anodic oxidation method. Surf. Coat. Technol. 2019, 380, 125078. [CrossRef]

18. Zhou, X.; Yu, S.; Guan, S.; Lv, Z.; Liu, E.; Zhao, Y. Fabrication and characterization of superhydrophobic $\mathrm{TiO}_{2}$ nanotube coating by a facile anodic oxidation approach. Surf. Coat. Technol. 2018, 354, 83-91. [CrossRef]

19. Su, J.; Tian, H.; Jiang, N. TRPIV experimental investigational of the effect of retrograde vortex on drag-reduction mechanism over superhydrophobic surfaces. Chin. J. Theor. Appl. Mech. 2016, 48, 1033-1039.

20. Ou, J.; Zhu, W.; Xie, C.; Xue, M. Mechanically Robust and Repairable Superhydrophobic Zinc Coating via a Fast and Facile Method for Corrosion Resisting. Materials 2019, 12, 1779. [CrossRef]

21. Ben, S.; Zhou, T.; Ma, H.; Yao, J.; Ning, Y.; Tian, D.; Liu, K.; Jiang, L. Multifunctional Magnetocontrollable Superwettable-Microcilia Surface for Directional Droplet Manipulation. Adv. Sci. 2019, 6, 1900834. [CrossRef] [PubMed]

22. Bhushan, B.; Jung, Y.C. Natural and biomimetic artificial surfaces for superhydrophobicity, self-cleaning, low adhesion, and drag reduction. Prog. Mater. Sci. 2011, 56, 1-108. [CrossRef]

23. Rafsanjani-Abbasi, A.; Rahimi, E.; Shalchian, H.; Vahdati-Khaki, J.; Babakhani, A.; Hosseinpour, S.; Davoodi, A. Recycled Cobalt from Spent Li-ion Batteries as a Superhydrophobic Coating for Corrosion Protection of Plain Carbon Steel. Materials 2018, 12, 90. [CrossRef] [PubMed]

24. Wu, L.; Yang, D.; Zhang, G.; Zhang, Z.; Zhang, S.; Tang, A.; Pan, F. Fabrication and characterization of Mg-M layered double hydroxide films on anodized magnesium alloy AZ31. Appl. Surf. Sci. 2018, 431, 177-186. [CrossRef]

25. Xie, J.; Hu, J.; Fang, L.; Liao, X.; Du, R.; Wu, F.; Wu, L. Facile fabrication and biological properties of super-hydrophobic coating on magnesium alloy used as potential implant materials. Surf. Coat. Technol. 2020, 384, 125223. [CrossRef]

26. Joo, J.; Kim, D.; Moon, H.-S.; Kim, K.; Lee, J. Durable anti-corrosive oil-impregnated porous surface of magnesium alloy by plasma electrolytic oxidation with hydrothermal treatment. Appl. Surf. Sci. 2020, 509, 145361. [CrossRef]

27. Zeng, Z.; Stanford, N.; Davies, C.; Nie, J.F.; Birbilis, N. Magnesium extrusion alloys: A review of developments and prospects. Int. Mater. Rev. 2018, 64, 27-62. [CrossRef]

28. Udhayan, R.; Bhatt, D.P. On the corrosion behaviour of magnesium and its alloys using electrochemical techniques. J. Power Sour. 1996, 63, 103-107. [CrossRef]

29. Li, H.; Feng, X.; Peng, Y.; Zeng, R.-C. Durable lubricant-infused coating on a magnesium alloy substrate with anti-biofouling and anti-corrosion properties and excellent thermally assisted healing ability. Nanoscale 2020, 12, 7700-7711. [CrossRef]

30. Guo, Z.; Liu, W.; Su, B.-L. Superhydrophobic surfaces: From natural to biomimetic to functional. J. Colloid Interface Sci. 2011, 353, 335-355. [CrossRef]

31. Chobaomsup, V.; Metzner, M.; Boonyongmaneerat, Y. Superhydrophobic surface modification for corrosion protection of metals and alloys. J. Coat. Technol. Res. 2020, 17, 583-595. [CrossRef]

32. Yin, B.; Fang, L.; Hu, J.; Tang, A.-Q.; Wei, W.-H.; He, J. Preparation and properties of super-hydrophobic coating on magnesium alloy. Appl. Surf. Sci. 2010, 257, 1666-1671. [CrossRef] 
33. Liu, Y.; Yin, X.; Zhang, J.; Yu, S.; Han, Z.; Ren, L. A electro-deposition process for fabrication of biomimetic super-hydrophobic surface and its corrosion resistance on magnesium alloy. Electrochim. Acta 2014, 125, 395-403. [CrossRef]

34. Liu, A.-H.; Xu, J.L. Preparation and corrosion resistance of superhydrophobic coatings on AZ31 magnesium alloy. Trans. Nonferrous Met. Soc. China 2018, 28, 2287-2293. [CrossRef]

35. Kang, Z.; Li, W. Facile and fast fabrication of superhydrophobic surface on magnesium alloy by one-step electrodeposition method. J. Ind. Eng. Chem. 2017, 50, 50-56. [CrossRef]

36. Wu, C.; Liu, Q.; Chen, R.; Liu, J.; Zhang, H.; Li, R.; Takahashi, K.; Liu, P.; Wang, J. Fabrication of ZIF-8@SiO 2 Micro/Nano Hierarchical Superhydrophobic Surface on AZ31 Magnesium Alloy with Impressive Corrosion Resistance and Abrasion Resistance. ACS Appl. Mater. Interfaces 2017, 9, 11106-11115. [CrossRef]

37. Liu, L.; Zhang, X.F.; Lei, J.L. Self-cleaning and Self-healing Protective Coating on Magnesium Alloy. Surf. Tech. 2019, 48, 27-33.

38. Ou, J.; Hu, W.; Li, C.; Wang, Y.; Xue, M.; Wang, F.; Li, W. Tunable Water Adhesion on Titanium Oxide Surfaces with Different Surface Structures. ACS Appl. Mater. Interfaces 2012, 4, 5737-5741. [CrossRef]

39. Jena, G.; Thinaharan, C.; George, R.; Philip, J. Robust nickel-reduced graphene oxide-myristic acid superhydrophobic coating on carbon steel using electrochemical codeposition and its corrosion resistance. Surf. Coat. Technol. 2020, 397, 125942. [CrossRef]

40. Jbeily, M.; Schwieger, C.; Kressler, J. Mixed Langmuir monolayers of perfluorostearic acid and stearic acid studied by epifluorescence microscopy using fluorinated rhodamines and infrared reflection absorption spectroscopy (IRRAS). Colloids Surf. A Physicochem. Eng. Asp. 2017, 529, 274-285. [CrossRef]

41. Griffth, E.C.; Adams, E.; Allen, H.C.; Vaida, V. Hydrophobic collapse of a steric acid film by adsorbed L-phenylalanine at the air-water interface. J. Phys. Chem. B 2012, 116, 7849-7857. [CrossRef] [PubMed]

42. Gunasekaran, S.; Natarajan, R.; Kala, A. FTIR spectra and mechanical strength analysis of some selected rubber derivatives. Spectrochim. Acta Part A Mol. Biomol. Spectrosc. 2007, 68, 323-330. [CrossRef] [PubMed]

43. Zhou, X.; Xu, D.; Yang, G.; Zhang, Q.; Shen, J.; Lu, J.; Zhang, K. Highly Exothermic and Superhydrophobic $\mathrm{Mg} /$ Fluorocarbon Core/Shell Nanoenergetic Arrays. ACS Appl. Mater. Interfaces 2014, 6, 10497-10505. [CrossRef] [PubMed]

44. Yathisha, R.; Nayaka, Y.A.; Purushothama, H.; Manjunatha, P.; Basavarajappa, K.; Vinay, M. Investigation the influence of $\mathrm{Zn2}+$ doping on the photovoltaic properties (DSSCs) of MgO nanoparticles. J. Mol. Struct. 2020, 1217. [CrossRef]

45. Shi, Z.; Liu, M.; Atrens, A. Measurement of the corrosion rate of magnesium alloys using Tafel extrapolation. Corros. Sci. 2010, 52, 579-588. [CrossRef]

46. Jaw, K.-S.; Hsu, C.-K.; Lee, J.-S. The thermal decomposition behaviors of stearic acid, paraffin wax and polyvinyl butyral. Thermochim. Acta 2001, 367, 165-168. [CrossRef] 